\title{
A PESQUISA EM EDUCAÇÃO MATEMÁTICA NA EDUCAÇÃO INFANTIL E NOS ANOS INICIAIS DO ENSINO FUNDAMENTAL: CONSIDERAÇÕES A PARTIR DOS RESUMOS DO GT 01 DO VI SIPEM
}

\author{
THE RESEARCH IN MATHEMATICS EDUCATION IN EARLY CHILDHOOD \\ EDUCATION AND ELEMENTARY EDUCATION INITIALS YEARS: CONSIDERATIONS \\ FROM THE WG 01 THE VI SIPEM SUMMARIES
}
LA INVESTIGACIÓN EN EDUCACIÓN MATEMÁTICA EN LA EDUCACIÓN INFANTIL Y EDUCACIÓN PRIMARIA AÑOS INICIALES: CONSIDERACIONES DE LOS RESÚMENES DEL GT 01 DEL VI SIPEM

Paulo Wichnoski ${ }^{1}$

\begin{abstract}
RESUMO
Este trabalho mapeou a produção em Educação Matemática na Educação Infantil e nos Anos Iniciais do Ensino Fundamental, a partir dos resumos dos trabalhos publicados no GT 01 do VI SIPEM ${ }^{2}$. Sob uma abordagem qualitativa de cunho fenomenológico-hermenêutico, buscou-se responder o que revelam os resumos dos trabalhos publicados neste evento sobre a pesquisa em Educação Matemática nos níveis de ensino supracitados. Os aspectos revelados se articularam em 4 categorias que dizem: 1) das características internas às pesquisas; 2) do focado e interrogado; 3) do respondido e 4) da autoria e instituições de vínculo dos autores. Em geral, as pesquisas se situam na fronteira entre a pedagogia, psicologia e matemática, convergindo com as demandas da área e apontam para a importância de conceber uma formação de professores não somente preocupada com o domínio do conceito matemático, mas com a compreensão da relação existente entre a linguagem matemática destes conceitos e a linguagem natural, favorecendo o processo de ensino.
\end{abstract}

PALAVRAS-CHAVE: Educação Matemática. Educação Infantil. Ensino Fundamental. Fenomenologia. Estado da Arte.

\begin{abstract}
This work mapped out the production in Mathematics Education in kindergarten and the Early Years of elementary school, from the abstracts of papers published in the WG 01 the VI SIPEM. About the qualitative approach of phenomenological-hermeneutical nature, we sought to answer what reveal the abstracts of papers published in this event on research in mathematics education in the aforementioned education levels. The disclosed aspects are articulated in four categories that say: 1) the internal characteristics to research; 2) the focused and interrogated; 3) of answered and 4) of authorship and link institutions of the authors. Overall the research are located on the border between pedagogy, psychology and mathematics, converging with the demands of the area and point to the importance of designing a teacher education not only concerned with the mathematical concept of the field, but with the understanding of the relationship between mathematics concepts and language of these natural language, favoring the teaching process.
\end{abstract}

KEYWORDS: Mathematics Education . Child Education . Elementary School . Phenomenology . State of art.

\footnotetext{
${ }^{1}$ Doutorando - Ensino de Ciências e Educação Matemática - Universidade Estadual do Oeste do Paraná (UNIOESTE) - Foz do Iguaçu, PR - Brasil. Mestrado em ensino - Universidade Estadual do Oeste do Paraná (UNIOESTE) - Foz do Iguaçu, PR - Brasil. Professor Visitante - Faculdade de Ampére (FAMPER) - Ampére, PR Brasil. E-mail: wichnoski@gmail.com

${ }^{2}$ Seminário Internacional de Pesquisa em Educação Matemática, promovido pela Sociedade Brasileira de Educação Matemática - SBEM.
}

Submetido em: 08/11/2016 - Aceito em: 15/02/2018 


\section{RESUMEN:}

Este trabajo mapeó la producción en Educación Matemática en la Educación Infantil y en los años iniciales de la Enseñanza Fundamental, a partir de los resúmenes de los trabajos publicados en el VI SIPEM. En un abordaje cualitativo de cuño fenomenológico-hermenéutico, se buscó responder lo que revelan los resúmenes de los trabajos publicados en este evento sobre la investigación en Educación Matemática en los niveles de enseñanza citados. Los aspectos revelados se articularon en 4 categorías que dicen 1) de las características internas a las investigaciones; 2 ) del enfoque e interrogado; 3 ) del respondido y 4) de la autoría e instituciones de vínculo de los autores. En general las investigaciones se sitúan en la frontera entre la pedagogía, la psicología y las matemáticas, convergiendo con las demandas del área. Se indica la necesidad de nuevos estudios que aclaren algunos resultados alcanzados, así como de estudios que aborden las tendencias en Educación Matemática.

PALABRAS - CLAVE: Educación Matemática. Educación Infantil. Enseñanza fundamental. La fenomenología. Estado del Arte.

\section{INTRODUÇÃO}

O movimento denominado Educação Matemática, constantemente, vem apontando perspectivas que se mostram importantes de serem discutidas no cenário educacional e da pesquisa, dentre elas, a Educação Matemática na Educação Infantil e nos Anos Iniciais do Ensino Fundamental.

Esta temática vem sendo abordada, por exemplo, em Passos (1995), Taxa (1996), Viana (2000), Starepravo (2010), Arruda (2011), Oliveira (2014), Santos (2015) entre outros, o que indica uma preocupação por parte dos pesquisadores que não é imediata. Contudo, ainda há possibilidades de discussões e estudos, uma vez que a pesquisa em Educação Matemática é algo em movimento e não se esgota em si.

Wichnoski e Klüber (2015b, p. 174) relatam que "Um dos modos de se adquirir um conhecimento profundo ou amplo de uma área de pesquisa, em geral, é o estudo bibliográfico", ainda mais quando a área apresenta amplas possibilidades de investigação. A Educação Matemática na Educação Infantil e nos Anos Iniciais do Ensino Fundamental pode ser assim caracterizada, como uma área fértil e aberta a investigações.

Desta forma, ela solicita o empreendimento de estudos com características bibliográficas e, dentre os modos de proceder, estão os estudos do tipo Estado da Arte, que possibilitam traçar um panorama da situação e do nível das pesquisas de determinado campo do conhecimento, em determinado momento. De acordo com Ferreira (2002, p. 258) estes estudos

possuem o desafio de mapear e de discutir uma certa produção acadêmica em diferentes campos do conhecimento, tentando responder que aspectos e dimensões vêm sendo destacados e privilegiados em diferentes épocas e lugares, de que formas e em que condições têm sido produzidas certas dissertações de mestrado, teses de doutorado, publicações em periódicos e comunicações em anais de congressos e de seminários. 
A necessidade de conhecer a própria pesquisa em determinada área e o estado em que ela se encontra fortalece a compreensão de aspectos fundamentais ao seu crescimento científico e

\begin{abstract}
é necessária no processo de evolução da ciência, afim de que se ordene periodicamente o conjunto de informações e resultados já obtidos, ordenação que permita indicação das possibilidades de integração de diferentes perspectivas, aparentemente autônomas, a identificação de duplicações ou contradições, e a determinação de lacunas e vieses (SOARES, 1989, p. 3).
\end{abstract}

Em face disso, e considerando que a Educação Matemática na Educação Infantil e nos Anos Iniciais do Ensino Fundamental é uma das demandas das pesquisas em Educação Matemática, buscou-se neste artigo mapear a produção científica nesta área e frente a um panorama geral, traçar modos, características e aspectos ausentes dessas pesquisas, bem como explicitar o que interrogam, quais resultados atingem, para que direções apontam, entre outros.

Para isso, consideraram-se como material de análise os trabalhos do GT 01 Educação Matemática na Educação Infantil e nos Anos Iniciais do Ensino Fundamental, publicados no VI SIPEM. Uma pesquisa com essa característica foi empreendida por Barreto et al. (2010) e buscou responder o que é a pesquisa em Educação Matemática nos Anos Iniciais no Brasil a partir dos textos do GT 01 publicados no III SIPEM. O trabalho ora apresentado denota objetivos comuns e considera o mesmo lócus de investigação do trabalho supramencionado, todavia difere em termos de edição do evento, procedimentos e análises.

Outros estudos do tipo Estado da Arte podem ser encontrados em Tambarussi e Klüber (2013), Wichnoski e Klüber (2015a) nos quais os autores realizam uma revisão de trabalhos acadêmicos, em nível de pós-graduação stricto sensu, buscando pelos focos que se mostram nas pesquisas em Modelagem Matemática, e em Investigação Matemática na Educação Matemática brasileira, respectivamente.

A escolha do evento se deu tendo em vista que ele se constitui em um importante espaço de divulgação e discussão das pesquisas que vem sendo empreendidas em âmbito internacional, nos diversos segmentos da Educação Matemática.

Ao que concerne a sua estrutura, o evento acontece em triênios e organiza-se por grupos integrados de pesquisa, os chamados Grupos de Trabalhos (GT's), que congregam pesquisadores brasileiros e estrangeiros de uma mesma área. No âmbito dos GT's, as pesquisas e as ações realizadas no triênio anterior são colocadas em pauta e discutidas pelos pares, recebendo contribuições que permitem o avanço, tanto das pesquisas, quanto das ações de divulgação e extensão destas. 
Em sua VI edição (abordada neste trabalho) o evento contou com 13 GT's, nomeadamente GT 01 - Matemática na Educação Infantil e nos Anos Iniciais do Ensino Fundamental, GT 02 - Educação Matemática nos Anos Finais do Ensino Fundamental, RT 03 Educação Matemática no Ensino Médio, GT 04 - Educação Matemática no Ensino Superior, GT - 05 História da Matemática e Cultura, GT 06 - Educação Matemática: novas tecnologias e educação a distância, GT 07 - Formação de professores que ensinam Matemática, GT 08 Avaliação em Educação Matemática, GT 09 - Processos cognitivos e linguísticos em Educação Matemática, GT 10 - Modelagem Matemática, GT 11 - Filosofia da Educação Matemática, GT 12 - Ensino de probabilidade e estatística e GT 13 - Diferença, Inclusão e Educação Matemática.

Apresentados os argumentos que justificam e tornam o trabalho relevante, a próxima seção será destinada a explicitação da metodologia assumida e dos procedimentos metodológicos adotados.

\section{SOBRE A METODOLOGIA DA PESQUISA E OS PROCEDIMENTOS METODOLÓGICOS}

O trabalho possui um caráter qualitativo que segundo Bicudo (2004, p.116) "engloba a ideia do subjetivo, passível de expor sensações e opiniões". Além disso, é uma forma de, através de um processo minucioso de investigação, por meio de métodos, técnicas e análises, buscar explicitar a compreensão, aquilo se mostra da essência dos fenômenos investigados.

Contudo, atribui-se a esta pesquisa uma visão fenomenológica, diferindo-a da pesquisa puramente qualitativa. As diferenças (aproximações e distanciamentos) se estabelecem a partir das atitudes assumidas diante da realidade, as quais refletem concepções distintas de mundo e de ciência. De acordo com Bicudo (2004, p.110)

O ponto que aproxima ambas está no qualitativo e em muitos recursos utilizados para investigar, está em muitos aspectos presentes na descrição da realidade, está no olhar em perspectiva. O que as diferencia é a pedra angular da fenomenologia: a intencionalidade e a atitude dela decorrente que já não é mais natural.

Assim, a busca pela compreensão da realidade se dá a partir de uma relação que não se estabelece de forma natural, mas de forma intencional, dada a partir da intencionalidade do sujeito sobre o objeto (fenômeno) que, fenomenologicamente, é intencional em correlação com a consciência.

$\mathrm{Na}$ atitude fenomenológica as manifestações do fenômeno se dão na percepção de quem percebe e, portanto, são dependentes da consciência, a qual "é movimento, é ato de expandir para, inclusive em sua própria direção. Esse movimento é o de voltar-se sobre os seus próprios atos e se refere ao ato de refletir ou à reflexão" (BICUDO, 2004, p.122). Por 
esta razão, se evidencia a linguagem, dando destaque à descrição e trabalhando com os sentidos e com os significados que fazem sentido àquele que percebe.

No tocante à análise dos dados, assumiu-se a análise hermenêutica, uma vez que ela privilegia os significados históricos e sociais atribuídos às manifestações daquilo que foi compreendido na percepção, mas foi traduzido em escritos e registros. Assim os dados são subjetivos, uma vez que são percepções de um sujeito para o qual o mundo tem um sentido próprio, mas também são intersubjetivos porque são sempre objetos intencionais, isto é, a relação é estabelecida para com o outro (BICUDO, 2004).

Essa compreensão em sentido lato permite retornar às mesmas obras, interrogandoas de maneira distinta e esclarecendo aspectos novos, de acordo com a interrogação de pesquisa construída na relação com o objeto intencional (BICUDO; KLÜBER, 2013). Além disso, permite: 1) Situar a Educação Infantil e os Anos Iniciais do Ensino Fundamental no contexto da Educação Matemática; 2) Enfocar hermeneuticamente a pesquisa realizada; 3) Investigar especificamente a produção em trabalhos publicados no GT 01 do VI SIPEM.

Buscando por aquilo que se mostra do fenômeno investigado (a pesquisa em Educação Matemática na Educação Infantil e nos Anos Iniciais do Ensino Fundamental), interrogou-se: o que revelam os resumos dos trabalhos publicados no GT 01 do VI SIPEM sobre a pesquisa em Educação Matemática na Educação Infantil e nos Anos Iniciais do Ensino Fundamental?

A interrogação solicitou uma pesquisa bibliográfica que, segundo Gil (2002, p. 65) "é desenvolvida a partir de material já elaborado, constituindo principalmente de livros e artigos científicos" e remeteu aos anais ${ }^{3}$ dos trabalhos publicados no GT 01 - Matemática na Educação Infantil e nos Anos Iniciais do Ensino Fundamental, no VI SIPEM.

Neste GT foram publicados 15 trabalhos, sendo eles: 1) Medeiros $(2015)^{4}$; 2) Guimarães e Oliveira $(2015)^{5}$; 3) Vieira e Nasser $(2015)^{6}$; 4) Pacheco e Pires $(2015)^{7}$; 5) Bellemain $(2015)^{8}$; 6) Silva e

\footnotetext{
${ }^{3}$ http://www.sbembrasil.org.br/visipem/anais/story.html

${ }^{4}$ MEDEIROS, Amanda Marina Andrade. Satisfação e Conhecimento Matemático: Uma Pesquisa Sobre Afetos com Alunos dos Anos Iniciais do Ensino Fundamental em uma Escola Pública do Distrito Federal, Brasil. In Seminário Internacional de Pesquisa em Educação Matemática, 6., Pirinópolis. Anais... Goiás, 1-12, 2015.

${ }^{5}$ GUIMARÃES, Gilda, OLIVEIRA, Izabella. Relação Entre Saber Classificar e o Domínio da Linguagem Oral Como Determinantes na Explicação Oral de Professores dos Anos Iniciais. In Seminário Internacional de Pesquisa em Educação Matemática, 6., Pirinópolis. Anais... Goiás, 1-15, 2015.

${ }^{6}$ VIEIRA, Edite Resende, NASSER, Lilian. PNAIC no Estado do Rio de Janeiro: Investigando as Práticas dos Formadores numa Perspectiva Interdisciplinar. In Seminário Internacional de Pesquisa em Educação Matemática, 6., Pirinópolis. Anais... Goiás, 1-13, 2015.

7 PACHECO, Débora Reis, PIRES, Célia Maria Carolino. Espaço e Forma nos Anos Iniciais e o Uso de Materiais Curriculares. In Seminário Internacional de Pesquisa em Educação Matemática, 6., Pirinópolis. Anais... Goiás, 1-12, 2015.

${ }^{8}$ BELLEMAIN, Paula Moreira Baltar. Ensinar Comprimento no Ciclo de Alfabetização. In Seminário Internacional de Pesquisa em Educação Matemática, 6., Pirinópolis. Anais... Goiás, 1-12, 2015.
}

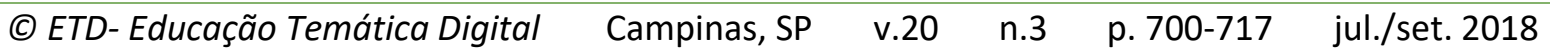


Borba $(2015)^{9}$; 7) Alencar $(2015)^{10}$; 8) Azerêdo $(2015)^{11}$; 9) Silva e Rodrigues $(2015)^{12}$; 10) Silva et. al. $(2015)^{13}$; 11) Tôrres e Muniz $(2015)^{14}$; 12) Junior et. al. $(2015)^{15}$; 13) Curi $(2015)^{16}$; 14) Vieira e Costa $(2015)^{17} ;$ 15) Marques e Silva $(2015)^{18}$.

Enumeradas de 1 a 15, conforme a disposição acima, inicialmente efetuou-se uma leitura sistemática ${ }^{19}$ dos resumos destas produções, buscando certa aproximação com o texto. Ressalta-se que, embora seja explicitado que esta pesquisa se dá a partir dos resumos, esporadicamente leu-se o conteúdo contido no corpo do texto para compreender alguns aspectos que não ficaram claros somente com a leitura dos resumos.

Posteriormente, dos resumos dos trabalhos publicados no GT 01 do VI SIPEM, foram destacadas as Unidades de Significados - US (BICUDO, 2011), entendidas como fragmentos do texto que fazem algum sentido ao pesquisador, em face da interrogação construída. Cada unidade foi identificada de acordo com a quantificação das unidades destacadas e o

9 SILVA, João Alberto, BORBA, Rute Elizabete de Souza Rosa. Desempenho de Estudantes em Itens sobre Tratamento da Informação na Provinha Brasil de Matemática. In Seminário Internacional de Pesquisa em Educação Matemática, 6., Pirinópolis. Anais... Goiás, 1-14, 2015.

${ }^{10}$ ALENCAR, Edvonete Souza. Os Referenciais Teóricos Norteadores de Pesquisas Sobre a Formação Contínua de Professores dos Anos Iniciais no Campo Conceitual Multiplicativo. In Seminário Internacional de Pesquisa em Educação Matemática, 6., Pirinópolis. Anais... Goiás, 1-12, 2015.

${ }^{11}$ AZERÊDO, Maria Alves. Registros Semióticos do Campo Multiplicativo: Um Instrumento Para o Ensino nos Anos Iniciais. In Seminário Internacional de Pesquisa em Educação Matemática, 6., Pirinópolis. Anais... Goiás, 1-13, 2015.

12 SILVA, Ricardo Scucuglia Rodrigues, RODRIGUES, Alana Fuzaro de Barros. A Produção de Performances Matemáticas Digitais nos Anos Iniciais do Ensino. In Seminário Internacional de Pesquisa em Educação Matemática, 6., Pirinópolis. Anais... Goiás, 1-13, 2015.

${ }^{13}$ SILVA, Angélica da Fontoura Garcia, CAMPOS, Tânia Maria Mendonça, CANOVA, Raquel Factori, PINHEIRO, Maria Gracilene de Carvalho. Equivalência em Situação Quociente: Uma Análise de Dois Estudos. In Seminário Internacional de Pesquisa em Educação Matemática, 6., Pirinópolis. Anais... Goiás, 1-12, 2015.

14 TÔRRES, Patrícia Lima, MUNIZ, Cristiano Alberto. Identificação e Análise de Conhecimentos Numéricos de Jovens e Adultos, em Explicações Orais e Escritas. In Seminário Internacional de Pesquisa em Educação Matemática, 6., Pirinópolis. Anais... Goiás, 1-12, 2015.

15 JUNIOR, Wallace Nascimento Pinto, TATAGIBA, Alessandro Borges, ALARCÃO, Clara Machado da Silva Alarcão, PEREIRA, Cátia Maria Machado da Costa, SOUTO, Waleska Karinne Soares Coutinho. Matrizes de Matemática do SAEB: Um Estudo Comparativo Entre 3o e 5o Anos do Ensino Fundamental. In Seminário Internacional de Pesquisa em Educação Matemática, 6., Pirinópolis. Anais... Goiás, 1-11, 2015.

${ }^{16}$ CURI, Edda. Orientações Curriculares, Livros Didáticos, Prova Brasil de Matemática do 5o ano e Práticas de Sala de Aula: Resultados de uma Pesquisa Longitudinal. In Seminário Internacional de Pesquisa em Educação Matemática, 6., Pirinópolis. Anais... Goiás, 1-13, 2015.

${ }_{17}$ VIEIRA, Edite Resende, COSTA, Nielce Meneguelo Lobo. Perspectivas de Mudanças no Ensino de Geometria com o Uso de Tecnologia Digital: Experiências em um Grupo de Estudos de Professores dos Anos Iniciais. In Seminário Internacional de Pesquisa em Educação Matemática, 6., Pirinópolis. Anais... Goiás, 1-13, 2015.

18 MARQUES, Valéria Risuenho, SILVA, Carlos Aldemir Farias. Alfabetização na Perspectiva da Racionalidade Aberta. In Seminário Internacional de Pesquisa em Educação Matemática, 6., Pirinópolis. Anais... Goiás, 1-11, 2015.

19 Segundo Severino (2002) nesta modalidade de leitura, o leitor acompanha o raciocínio expositivo e dissertativo do autor, ou seja, o leitor decodifica a mensagem. Assim, o leitor tem uma compreensão global do texto, facilitando sua interpretação crítica e a possibilidade de estabelecer um diálogo com o conjunto da cultura. 
número do texto, respectivamente. Assim, por exemplo, a Unidade de Significado (1.4) trata-se da unidade um do texto quatro. Para cada uma realizou-se uma interpretação, considerando o contexto em que ela se encontrava no texto, conforme exemplificado no quadro 1.

QUADRO 1 - Exemplos de Unidades de Significados - US

\begin{tabular}{|c|c|}
\hline Excertos & Unidade de Significado \\
\hline $\begin{array}{l}\text { Junto aos formadores de Matemática, foi possível } \\
\text { atuar de forma interdisciplinar, desenvolvendo } \\
\text { atividades favoráveis à construção dos } \\
\text { conhecimentos e práticas pedagógicas pelos } \\
\text { Orientadores de Estudos. (7.3) }\end{array}$ & $\begin{array}{l}\text { A interdisciplinaridade possibilita a } \\
\text { construção de conhecimentos e } \\
\text { favorece a prática pedagógica docente } \\
\text { para o ensino de matemática. }\end{array}$ \\
\hline $\begin{array}{l}\text { Os resultados apontam que os professores utilizam } \\
\text { os materiais de diferentes modos, reproduzem, } \\
\text { adaptam ou criam situações, refletindo suas } \\
\text { concepções e conhecimentos. Assim, a qualidade } \\
\text { da prática docente depende das contribuições do } \\
\text { material e dos seus recursos do professor. (9.4) }\end{array}$ & $\begin{array}{l}\text { A pesquisa conclui que os professores } \\
\text { adequam, adaptam e criam situações } \\
\text { de ensino, com o material curricular, } \\
\text { de acordo com suas concepções e } \\
\text { conhecimentos. }\end{array}$ \\
\hline $\begin{array}{l}\text { Cujo objetivo foi identificar e analisar a produção } \\
\text { de conhecimentos matemáticos em diferentes } \\
\text { graus de formalização e explicitação oral e escrita, } \\
\text { de caráter cognitivo e metacognitivo. (6.11) }\end{array}$ & $\begin{array}{l}\text { A pesquisa } \\
\text { cognitivos considera aspectos } \\
\text { associados à aprendizagem de } \\
\text { matemática. }\end{array}$ \\
\hline
\end{tabular}

Fonte: o autor

Diante dos excertos e respectivas interpretações buscaram-se convergências sucessivas, primeiramente construindo algumas ideias nucleares e por fim os núcleos de ideias ou categorias de análises, as quais são explicitadoras do revelado pelos resumos dos trabalhos publicados no GT 01 do VI SIPEM sobre a pesquisa em Educação Matemática na Educação Infantil e nos Anos Iniciais do Ensino Fundamental. A fim de exemplificar a construção das categorias de análises de acordo com as convergências das Unidades de Dignificados destacadas nos resumos dos trabalhos, apresento o quadro 2 . 


\section{QUADRO 2 - Exemplo de categoria}

C1 Sobre as características internas às pesquisas - Esta categoria é composta pelas unidades de significados abaixo destacadas e explicita os aspectos internos às pesquisas como contexto, abordagem, participantes, tipos e níveis das pesquisas, metodologia empregada e procedimentos metodológicos (modos de recolha e análises dos dados) e sobre os objetivos mais gerais. Expressa a abrangência das pesquisas em sentido lato.

\begin{tabular}{|c|}
\hline Unidades de Significados (US) \\
\hline $\begin{array}{l}\text { Recorte de uma pesquisa de doutorado em } \\
\text { andamento (5.15) }\end{array}$ \\
\hline $\begin{array}{l}\text { Apresentamos resultados iniciais de uma pesquisa em } \\
\text { desenvolvimento (5.9) }\end{array}$ \\
\hline Pesquisa documental (4.13) \\
\hline $\begin{array}{l}\text { O presente artigo traz um recorte de resultados de } \\
\text { tese de doutorado (5.11) }\end{array}$ \\
\hline $\begin{array}{l}\text { Este trabalho apresenta os resultados de um estudo } \\
\text { comparativo (11.12) }\end{array}$ \\
\hline $\begin{array}{l}\text { Este trabalho apresenta resultados de um estudo } \\
\text { comparativo entre as Matrizes de referências dos } 3^{\circ} \text { e } \\
5^{\circ} \text { anos do Sistema da Avaliação da Educação Básica } \\
\text { (Saeb) para a área de matemática (12.12) }\end{array}$ \\
\hline $\begin{array}{l}\text { Esta comunicação apresenta a trajetória de uma } \\
\text { pesquisa de doutoramento que analisou, em um grupo } \\
\text { de estudos, constituído na escola (5.14) }\end{array}$ \\
\hline
\end{tabular}

Foi utilizada uma abordagem qualitativa. Para a construção dos dados o pesquisador inseriu-se no ambiente escolar e teve como uma das técnicas a observação participante registrada em diário de campo (8.1)

Metodologicamente trata-se de um estudo qualitativo no qual produzimos dados a partir da realização de sessões de ensino com quatro turmas (7.9)

A metodologia associou entrevista clínica à microanálise (8.11)

Neste trabalho são apresentados protocolos de três educando matriculados em uma escola pública de primeiro segmento de Educação de Jovens e Adultos (7.11)

Cada item foi respondido por 40 crianças, investigando seus desempenhos e estratégias empregadas (6.6)

Organizou-se no colégio Pedro II um grupo formado por três professoras dos anos iniciais e a autora desta comunicação (7.14)

Professor dos anos iniciais (4.2)

São analisados documentos de orientação curricular de abrangência nacional e uma coleção de livros didáticos para o ciclo de alfabetização (3.5)

Investigaram a compreensão de alunos do quinto ano do ensino fundamental acerca da equivalência de números racionais em sua representação fracionaria (10.10)

Unidades de Significados (US)

São investigações de natureza qualitativa (12.10)

Este artigo apresenta os resultados de dois estudos (9.10) Análise documental (14.12)

O presente artigo é resultado parcial de uma pesquisa (3.7)

Nesse artigo apresentamos um recorte da nossa pesquisa de mestrado (5.4)

A entrevista com alunos participantes da pesquisa também foi um instrumento importante para entender a relação entre a satisfação e o conhecimento matemático (9.1)

Estes estudos foram realizados no contexto de um projeto de formação e pesquisa envolvendo pesquisadores e professores (11.10)

Nossa pesquisa é qualitativa de caráter bibliográfico, na qual realizamos uma busca no banco de teses da capes, para selecionar dissertações e teses brasileiras (5.7)

Discute-se o ensino do campo multiplicativo a partir dos registros semióticos produzidos pelos estudantes (3.8)

Os dados discutidos são recortes de uma pesquisa mais ampla (4.8)

A imersão em uma sala de aula dos anos iniciais possibilitou analisar a afetividade das crianças, incluindo a satisfação pelo conhecimento matemático (10.1)

Para compreender a relação do professor com o material curricular nos baseamos nos estudos de Brown (2009) (7.4)

O processo de apropriação de tecnologia digital no ensino de geometria e o conhecimento profissional docente (6.14) Alunos do $3^{\circ}$ e $5^{\circ}$ ano (5.8)

A pesquisa propõe uma investigação sobre o uso de materiais curriculares por duas professoras dos anos iniciais do Ensino Fundamental (6.4)

Utilizamos como instrumento de pesquisa a análise de material curricular, observações de aulas em que o material foi colocado em prática e entrevistas (8. 4)

A metodologia adotada foi a qualitativa com Tema central alfabetização (matemática) sob a
características da pesquisa co-generativa (8.14) perspectiva múltipla e plural (6.15)

Fonte: o autor 
Desse movimento fenomenológico resultaram quatro categorias, as quais são descritas no quadro abaixo e na próxima seção, interpretadas à luz da interrogação $o$ que revelam os resumos dos trabalhos publicados no GT 01 no VI SIPEM sobre a pesquisa em Educação Matemática na Educação Infantil e nos Anos Iniciais do Ensino Fundamental?

QUADRO 3 - Categorias de análise e descrição

\begin{tabular}{|c|c|c|}
\hline Categorias & Descrição & $\begin{array}{c}\text { Número } \\
\text { de US }\end{array}$ \\
\hline $\begin{array}{l}\mathrm{C} 1 \text { - Sobre as } \\
\text { características } \\
\text { internas às } \\
\text { pesquisas }\end{array}$ & $\begin{array}{l}\text { Esta categoria explicita os aspectos internos às pesquisas } \\
\text { como contexto, abordagem, sujeitos participantes, tipos e } \\
\text { níveis das pesquisas, metodologia empregada e } \\
\text { procedimentos metodológicos (modos de recolha e } \\
\text { análises dos dados) e sobre os objetivos mais gerais. }\end{array}$ & 34 \\
\hline $\begin{array}{l}\text { C2 - Sobre o focado } \\
\text { e interrogado nas } \\
\text { pesquisas }\end{array}$ & $\begin{array}{l}\text { Esta categoria é reveladora do focado, interrogado e } \\
\text { discutido pelas pesquisas. Explicita os caminhos, } \\
\text { interrogações e objetivos perseguidos ao longo dos } \\
\text { trabalhos. }\end{array}$ & 15 \\
\hline $\begin{array}{l}\text { C3 - Sobre o } \\
\text { respondido nas } \\
\text { pesquisas }\end{array}$ & $\begin{array}{l}\text { Esta categoria revela as conclusões das pesquisas, aquilo } \\
\text { que foi respondido ante o interrogado. Manifesta os } \\
\text { resultados, seja de modo parcial ou total, que foram } \\
\text { discutidos no âmbito do GT. }\end{array}$ & 29 \\
\hline $\begin{array}{l}\text { C4 - Sobre a autoria } \\
\text { e instituições de } \\
\text { vínculo }\end{array}$ & $\begin{array}{l}\text { Esta categoria traz aspectos inerentes aos autores das } \\
\text { pesquisas, bem como as respectivas instituições de } \\
\text { filiação que se fizeram presentes no âmbito do GT. }\end{array}$ & 62 \\
\hline
\end{tabular}

Fonte: o autor

\section{INTERPRETAÇÃO DAS CATEGORIAS}

Nesta seção serão explicitados os manifestos emergentes em cada categoria que, em algum sentido, são reveladores do fenômeno interrogado. Iniciar-se-á com uma breve descrição de cada categoria seguida das reflexões resultantes do movimento interpretativo efetuado.

A categoria C1 - Sobre as características internas às pesquisas explicita os aspectos gerais das pesquisas tais como: o contexto em que elas ocorreram, a abordagem assumida, os participantes, os tipos das pesquisas, os níveis em que elas se encontram, a metodologia empregada e procedimentos metodológicos (modos de recolha e análises dos dados). 
Na sua totalidade de natureza qualitativa, as pesquisas apresentadas no VI SIPEM, no âmbito do GT 01, são estudos individuais ou estudos que derivam de outras investigações mais amplas, como projeto de formação, projeto de pesquisa, dissertações de mestrado e teses de doutorado em andamento ou concluídas. Em geral trazem resultados parciais frente a recortes das investigações mais amplas.

Contudo, destacaram-se dois trabalhos atípicos a essa característica, um apresentando resultados iniciais de uma pesquisa em desenvolvimento e, em contrapeso, outro apresentando resultados finais de uma pesquisa de doutorado. É fato que os resultados iniciais em certo sentido também são parciais, no entanto chamaram atenção por serem resultados ainda exploratórios, embora não tenha sido possível detectar a qual momento da pesquisa esses resultados, ditos parciais, se referem. Outra atipicidade foi um trabalho que sintetizou resultados de dois estudos empreendidos em uma mesma perspectiva, realizados no mesmo contexto, em momentos diferentes.

Com relação ao delineamento das pesquisas, revela-se que as modalidades empírica, bibliográfica e documental foram predominantes. As pesquisas de caráter empírico ocorrem no contexto de projetos de formação e de pesquisa (pesquisa cogenerativa) e no ambiente escolar, tendo alunos regulares dos Anos Iniciais do Ensino Fundamental $\left(2^{\circ}, 3^{\circ}, 4^{\circ}\right.$ e $5^{\circ}$ ano), alunos da Educação de Jovens e Adultos que estão cursando este nível de ensino, professores atuantes neste mesmo nível e futuros professores dos Anos Iniciais (graduandos de pedagogia do Recife - Brasil, de Burgos - Espanha e de Quebec - Canadá), como participantes.

Dentre as pesquisas empreendidas no âmbito escolar, revelaram-se duas pesquisas realizadas em contextos pedagógicos diferenciados. Em uma, a diferença reside numa proposta educacional voltada ao desenvolvimento da singularidade cognitiva/espiritual dos estudantes, em combinação com a efetiva participação de todos os pais/responsáveis, e apresenta como fundamentos teóricos "a pedagogia de projetos e as inteligências múltiplas" (GARDNER, 1993). Na outra a diferença está nas características sociais e culturais da escola, a qual está inserida numa comunidade ribeirinha.

Já as pesquisas de cunho documental se debruçaram sobre documentos curriculares nacionais, como por exemplo, Referencial Curricular Nacional para a Educação Infantil RCNEI (BRASIL, 1998) e os Parâmetros Curriculares Nacionais de Matemática - PCN (BRASIL, 1997), prova de avaliações externas, como por exemplo, provinha Brasil de matemática SAEB, material curricular para a prática do professor e livros didáticos. Com caráter bibliográfico manifestou-se a presença de apenas um trabalho, o qual se debruçou sobre as produções científicas brasileiras da área. 
A coleta de dados se deu com entrevistas semiestruturadas, entrevistas clínicas, observações participantes, diários de campo, gravações em áudio e transcrições de sessões de ensino, aplicação de questões para resolução e busca em portais de periódicos com acesso livre. Com relação ao modo de proceder às análises, somente um trabalho o explicitou, a saber: microanálise.

A categoria C2 - Sobre o focado e interrogado nas pesquisas explicita os caminhos, interrogações e objetivos perseguidos ao longo dos trabalhos.

Revela que os trabalhos publicados no GT 01 do VI SIPEM, possuem como focos de pesquisas: a formação inicial e continuada de professores dos Anos Iniciais de escolarização (Educação Infantil) e do Ensino Fundamental; o conhecimento matemático de estudantes deste nível de ensino em sala de aula e para além deste universo; o conhecimento matemático de graduandos do curso de pedagogia frente a alguns conceitos; a alfabetização matemática; bem como, os aspectos relacionados à afetividade dos alunos para com a matemática e às emoções de formadores de professores alfabetizadores de Língua Portuguesa e Matemática.

Além disso, os trabalhos enfocaram a produção do conhecimento matemático em diferentes graus de formalização e explicitação oral e escrita, o ensino e aprendizagem da matemática do ponto de vista teórico-metodológico, a presença da satisfação por parte dos alunos no processo de ensino e aprendizagem, os recursos didáticos para o ensino de matemática e a formação de professores, como por exemplo, o processo de apropriação de tecnologia digital no ensino de geometria, e o conhecimento profissional docente.

Um trabalho interrogou a própria pesquisa na área com o objetivo de realizar uma metassíntese a respeito da formação continuada de professores da Educação Infantil e dos Anos Iniciais do Ensino Fundamental, sobre o campo conceitual multiplicativo ${ }^{20}$. 0 campo multiplicativo é enfocado em outro trabalho a partir dos registros semióticos produzidos pelos estudantes em face de tarefas propostas em sala de aula.

Ao enfocarem documentos curriculares, os trabalhos interrogam convergências e inconsistências nestes documentos, como por exemplo, se há convergência entre o que os referenciais curriculares preconizam e o que os livros didáticos propõem para o ensino de matemática; e o modo como alguns temas matemáticos são abordados nas várias instâncias curriculares.

A categoria C3 - Sobre o respondido nas pesquisas revela aquilo que foi respondido ante o interrogado. Manifesta os resultados, seja de modo parcial ou total, que foram

\footnotetext{
${ }^{20}$ É um conceito da teoria dos campos conceituais de Vergnaud (1990) que designa o conjunto das situações
} que envolvem as operações de multiplicação e divisão e todos os conceitos e teoremas interligados a elas. 
discutidos no âmbito do GT 01 no VI SIPEM. Em geral eles são apresentados qualitativamente, embora alguns trabalhos os apresentaram, em partes, de modo quantitativo. Para uma organização das ideias, ordenar-se-á a explicitação do revelado acerca das pesquisas empíricas, bibliográficas e documentais, respectivamente.

No tocante aos resultados provenientes das pesquisas empíricas revela-se que a prática profissional do professor ocorre próxima da concepção e dos conhecimentos que carregam histórica e socialmente, com influência do que estudaram no ensino básico. 0 currículo prescrito e, por vezes, o livro didático não são utilizados pelos professores, os quais mencionaram buscar atividades na internet ou em avaliações nacionais externas e quando são utilizados, os professores "reproduzem, adaptam ou criam situações, refletindo suas concepções e conhecimentos" (9.4).

A constituição de grupos de estudos ou de formação mostrou-se favorável ao processo de apropriação e de aprimoramento dos conhecimentos profissionais, promovendo mudanças de paradigmas, concepções e de comportamentos face ao conhecimento e a prática docente. A interdisciplinaridade também despontou como aspecto positivo para esse fim.

Evidenciou-se que a interação entre os formadores e professores propiciou a reflexão e o planejamento compartilhado, ao menos no âmbito de uma proposta de formação para professores alfabetizadores envolvidos no Pacto Nacional Pela Alfabetização na Idade Certa - PNAIC.

Com relação à aprendizagem da matemática, os resultados indicaram que ela depende de vários fatores, dentre eles, da subjetividade e da afetividade das crianças no espaço escolar, da satisfação pelo conhecimento matemático, dos modos de apresentação das tarefas, dos contextos envolvidos e dos valores numéricos, podendo ser potencializada com a utilização de diferentes registros semióticos.

Sinalizam para a necessidade da promoção da capacidade de conversão e tratamento entre diferentes registros, como por exemplo, texto $\rightarrow$ problema $\rightarrow$ figura $\rightarrow$ algoritmo, não necessariamente nesta ordem e direção, uma vez que eles apareceram de "forma variada nas resoluções apresentadas pelos alunos, no entanto o algoritmo formal foi utilizado somente por alunos do $5^{\circ}$ ano" (6.8). Além disso, salientou-se que a conversão entre texto e desenho exerce o papel de mediação entre o texto e algoritmo, o que influencia no aumento do número de acertos de questões propostas.

Em contraponto a isso, uma pesquisa salienta que os desempenhos interpretativos e resolutivos de questões matemáticas não dependem do uso de imagens e que tal uso nem sempre favorece a compreensão. Segundo os autores, "as crenças da melhora de 
desempenho na avaliação devido ao uso de imagens ou de que contextos familiares facilitam o raciocínio, não se confirmaram no estudo realizado" (8.6).

A aprendizagem de conceitos matemáticos abordados nos níveis infantil e fundamental de ensino, quando ocorrida por sujeitos fora da faixa etária considerada certa pelos documentos oficiais (BRASIL, 2014), como é o caso da Educação de Jovens e Adultos, depende de fatores como o contrato didático estabelecido entre professor e alunos, as crenças e intuições particulares acerca da matemática, a pré-disposição em aprender, a autorregulação desse processo, bem como a capacidade de questionar os conhecimentos aprendidos. Ao ser tematizada no nível de graduação (curso de pedagogia) a aprendizagem de conceitos matemáticos mostrou-se dúbia, havendo dificuldades em ser expressa de forma oral.

Os resultados provenientes do estudo que tematizou o uso das artes performáticas e das tecnologias digitais em Educação Matemática, performance matemática digital - PMD, embora exploratórios, acusaram limitações desta possibilidade metodológica com relação à produção de significados matemáticos, porém não as explicitaram.

Ao que concerne às pesquisas de cunho bibliográfico, os resultados destacaram coerência entre os documentos curriculares e de avaliação analisados, no que tange aos objetivos, expectativas de aprendizagem e descritores de avaliação. Contudo, denunciaram lacunas na abordagem de alguns temas, nos livros didáticos.

Particularizando o tema comprimento, os resultados mostraram que ele é tratado nos materiais curriculares como parte do domínio das grandezas e medidas, ancorado nos seus usos sociais, nas conexões com a geometria, com a aritmética e nas articulações com outros componentes curriculares. Além disso, mostraram que há uma variedade significativa de tarefas abordando este tema, porém com ênfase "no uso de unidades e instrumentos convencionais, o que é divergente do preconizado nas orientações curriculares" (6.5).

O único trabalho de cunho documental, o qual aborda a formação continuada de professores dos anos iniciais no Campo Conceitual Multiplicativo em dissertações e teses brasileiras, conclui que o foco dos estudos está no desenvolvimento profissional apontado por Lee S. Shulman, nos saberes docentes apresentados por Maurice Tardif, na prática reflexiva abordada por Donald Schön e Kenneth Zeickner e nos aspectos abordados nas pesquisas sobre formação de professores na perspectiva apresentada por Dario Fiorentini.

A categoria C4 - Sobre a autoria e instituições de vínculo revela aspectos inerentes aos autores das pesquisas, bem como as respectivas instituições de filiação que se fizeram presentes no âmbito do GT 01 no VI SIPEM. O quadro 4 apresenta uma síntese das informações referentes à autoria dos trabalhos. 
QUADRO 4 - Informações sobre os autores

\begin{tabular}{|c|c|c|c|}
\hline $\begin{array}{c}\text { Identificação } \\
\text { do autor }\end{array}$ & Nome do autor & Instituição de filiação & País \\
\hline 1 & $\begin{array}{l}\text { Alana Fuzaro de Barros } \\
\text { Rodrigues }\end{array}$ & Escola Maria Peregrina & Brasil \\
\hline 2 & Alessandro Borges Tatagiba & $\begin{array}{c}\text { Instituto Nacional de Estudos e Pesquisas } \\
\text { Educacionais Anísio Teixeira }\end{array}$ & Brasil \\
\hline 3 & $\begin{array}{l}\text { Amanda Marina Andrade } \\
\text { Medeiros }\end{array}$ & Universidade de Brasília & Brasil \\
\hline 4 & $\begin{array}{l}\text { Angélica da Fontoura Garcia } \\
\text { Silva }\end{array}$ & Universidade Anhanguera & Brasil \\
\hline 5 & Carlos Aldemir Farias da Silva & Universidade Federal do Pará & Brasil \\
\hline 6 & $\begin{array}{l}\text { Cátia Maria Machado da Costa } \\
\text { Pereira }\end{array}$ & $\begin{array}{c}\text { Instituto Nacional de Estudos e Pesquisas } \\
\text { Educacionais Anísio Teixeira } \\
\end{array}$ & Brasil \\
\hline 7 & Célia Maria Carolino Pires & Universidade Federal do Mato Grosso do Sul & Brasil \\
\hline 8 & Clara Machado da Silva Alarcão & $\begin{array}{c}\text { Instituto Nacional de Estudos e Pesquisas } \\
\text { Educacionais Anísio Teixeira }\end{array}$ & Brasil \\
\hline 9 & Cristiano Alberto Muniz & Universidade de Brasília & Brasil \\
\hline 10 & Débora Reis Pacheco & Pontifícia Universidade Católica & Brasil \\
\hline 11 & Edda Curi & Universidade Cruzeiro do Sul & Brasil \\
\hline 12 & Edite Resende Vieira & Colégio Pedro II & Brasil \\
\hline 13 & Edvonete Souza de Alencar & Pontifícia Universidade Católica & Brasil \\
\hline 14 & Gilda Guimarães & Universidade Federal de Pernambuco & Brasil \\
\hline 15 & Izabella Oliveira & Université Laval & Canadá \\
\hline 16 & João Alberto da Silva & Universidade Federal do Rio Grande & Brasil \\
\hline 17 & Lilian Nasser & Universidade Federal do Rio de Janeiro & Brasil \\
\hline 18 & Maria Alves de Azerêdo & Universidade Federal da Paraíba & Brasil \\
\hline 19 & $\begin{array}{l}\text { Maria Gracilene de Carvalho } \\
\text { Pinheiro }\end{array}$ & Universidade Anhanguera & Brasil \\
\hline 20 & $\begin{array}{l}\text { Nielce Meneguelo Lobo da } \\
\text { Costa }\end{array}$ & Universidade Anhanguera & Brasil \\
\hline 21 & Patrícia Lima Tôrres & Universidade de Brasília & Brasil \\
\hline 22 & Paula Moreira Baltar Bellemain & Universidade Federal de Pernambuco & Brasil \\
\hline 23 & Raquel Factori Canova & Universidade Anhanguera & Brasil \\
\hline 24 & $\begin{array}{l}\text { Ricardo Scucuglia Rodrigues da } \\
\text { Silva }\end{array}$ & Universidade Estadual Paulista & Brasil \\
\hline 25 & $\begin{array}{l}\text { Rute Elizabete de Souza Rosa } \\
\text { Borba }\end{array}$ & Universidade Federal de Pernambuco & Brasil \\
\hline 26 & Tânia Maria Mendonça Campos & Universidade Anhanguera & Brasil \\
\hline 27 & Valéria Risuenho Marques & Secretaria Municipal de Educação de Belém & Brasil \\
\hline 28 & $\begin{array}{l}\text { Waleska Karinne Soares } \\
\text { Coutinho Souto }\end{array}$ & $\begin{array}{c}\text { Instituto Nacional de Estudos e Pesquisas } \\
\text { Educacionais Anísio Teixeira }\end{array}$ & Brasil \\
\hline 29 & $\begin{array}{l}\text { Wallace Nascimento Pinto } \\
\text { Junior }\end{array}$ & $\begin{array}{c}\text { Instituto Nacional de Estudos e Pesquisas } \\
\text { Educacionais Anísio Teixeira }\end{array}$ & Brasil \\
\hline
\end{tabular}

Fonte: o autor

A produção em Educação Matemática na Educação Infantil e nos Anos Iniciais do Ensino Fundamental, no âmbito do evento, se mostra com bastante veemência e está, notadamente, vinculada a autores e instituições brasileiras localizadas nos estados de São
(C) ETD-Educação Temática Digital
Campinas, SP
v. 20 n.3
p. $700-717$
jul./set. 2018 
Paulo - SP, Mato Grosso do Sul - MS, Rio de Janeiro - RJ, Brasília - DF, Pernambuco - PE, Pará - PA, Paraíba - PB e Rio Grande do Sul - RS. Houve apenas um trabalho vinculado a uma instituição internacional, porém, produzido em coautoria com autor nacional.

Dos 15 trabalhos publicados no GT 01 do VI SIPEM, 10 foram realizados em coautoria. Destes, 2 foram entre professores universitários vinculados a mesma instituição $\left(9 / 21^{21}, 4 / 19 / 23 / 26\right), 3$ entre professores universitários vinculados à instituições distintas $(16 / 25,14 / 15,7 / 10)$ - aqui destaca-se uma parceria entre uma universidade nacional (Universidade Federal de Pernambuco) e outra internacional (Université Laval) -, 4 entre professores universitários e professores da Educação Básica $(5 / 27,12 / 17,1 / 24,12 / 20)$ e 1 entre membros de um instituto de estudos e pesquisas em educação (INEP) (2/6/8/28/29).

\section{ALGUMAS CONSIDERAÇÕES METACOMPREENSIVAS}

Ante ao interrogado e revelado em cada categoria, em síntese, as pesquisas se revelaram situadas na fronteira da pedagogia, enquanto ciência que estuda os problemas relacionados ao desenvolvimento educativo, da matemática enquanto região de inquérito desses problemas e da psicologia, enquanto conhecimento científico que disponibiliza instrumentos para compreendermos os processos educativos.

Os focos das pesquisas não se mostraram isolados e direcionados somente pela subjetividade do pesquisador mesmo que esta se faz presente "desde a escolha dos objetos, passando pelo estabelecimento das hipóteses, seleção e recorte do campo de estudo até as análises e interpretações" (BRITO; LEONARDOS, 2001, p. 8).

Há certa convergência, não no sentido de as pesquisas possuírem mesmo foco, mas de empenharem-se para atender a demanda de carências, objetivos e explicações que a área solicita, considerando a temporalidade em que se encontrava, o que revelou um direcionamento por parte dos pesquisadores para assuntos que merecem atenção e requerem discussões.

Elas apontam para a importância de conceber uma formação de professores não somente preocupada com o domínio do conceito matemático, mas que os levem a compreender a relação que existe entre a linguagem matemática pertinente a estes conceitos e a linguagem natural, favorecendo as explicações dadas em sala. Isso revela que as pesquisas em Educação Matemática na Educação Infantil e nos Anos Iniciais do Ensino Fundamental estão em consonância com as demandas da Educação Matemática, enquanto campo de estudo mais amplo, uma vez que esta preocupação se mostra também em outras instâncias em que ela se presentifica.

\footnotetext{
${ }^{21}$ Trabalho produzido em coautoria entre os autores 9 e 21.
}

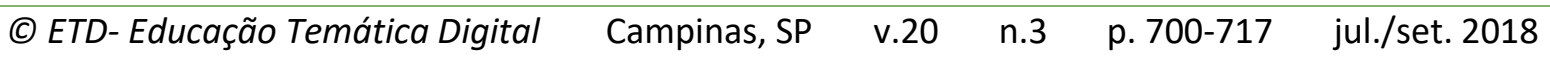


Além disso, no âmbito do VI SIPEM a produção científica em Educação Matemática nestes níveis de ensino se mostrou construída, em sua maioria, no cenário nacional. Talvez isso deve-se ao fato de que o evento é uma iniciativa brasileira, contudo isso não exclui a possibilidade de autores internacionais publicarem trabalhos. Porém, a presença dos autores no SIPEM é uma das características e exigência do evento, uma vez que o objetivo é promover o intercâmbio, o encontro entre pesquisadores que se dedicam a uma mesma área e a possibilidade de conhecer e debater as investigações que estão sendo realizadas e isso pode ter influenciado na falta de trabalhos internacionais.

Embora os resumos não exprimam o trabalho na sua totalidade, eles devem informar o leitor, enquanto gênero do discurso, sobre os objetivos, os aspectos metodológicos e os resultados alcançados na pesquisa (FERREIRA, 2002). Em face disto, destaco que no âmbito do GT 01 do VI SIPEM, somente um trabalho destacou no resumo os procedimentos metodológicos adotados. Esta ausência da explicitação dos elementos que compõe a estrutura básica de um resumo, em particular do procedimento de análise, é prejudicial, pois há razões para supor que a falta de explicitação desses elementos empobrece a produção científica na área.

Concernente a prática profissional do professor, que revelou-se amparada em conhecimentos histórica e socialmente construídos, sendo influenciada também pelo modo que foram ensinados no ensino básico, há razões para supor que sua formação inicial foi incipiente para promover modos específicos de trabalhar a matemática, bem como para promover a (des)construção de concepções e paradigmas. Tais insuficiências promovem implicações diretas na prática docente do professor.

O reflexo das concepções e dos conhecimentos subjetivos do professor implicou, por vezes, em uma reconfiguração do currículo escolar e na adaptação de situações de ensino. Por um lado, isto revela um desapego do livro didático e do segmento rigoroso do currículo que é significativo, por outro, sendo os conhecimentos que pautam essas adaptações, por vezes particulares, há o risco de o professor reconfigurar o ensino de matemática sem amparo científico.

Um dos trabalhos analisados apresentou um estudo sobre os registros de representações semióticas (DUVAL, 2009) do campo multiplicativo (VERGNAUD, 1990) e concluiu que o registro desenho potencializa a compreensão das questões e, consequentemente, aumenta o índice de acertos, conforme relatado: "Sobre a conversão entre texto-desenho, os resultados indicaram aumento no índice de acerto, o que nos aponta para o papel de mediação exercido pelo registro desenho" (AZERÊDO, 2015).

Outro trabalho abordou o tratamento da informação e concluiu que o uso de imagens, além de outros fatores, não contribui para um melhor desempenho na resolução das questões e relata: "Crenças usuais, tais como a melhora de desempenho na avaliação

$\begin{array}{llllll}\text { (C) ETD-Educação Temática Digital } & \text { Campinas, SP } & \text { v.20 } & \text { n.3 } & \text { p. 700-717 } & \text { jul./set. } 2018\end{array}$


devido ao uso de imagens [...] facilitam o raciocínio, não se confirmaram no estudo realizado" (SILVA; BORBA, 2015).

Em face destes dois trabalhos supramencionados, instaura-se a necessidade de empreender estudos pormenorizados que esclareçam, a partir das respostas fornecidas pelos alunos ao resolverem questões matemáticas, em que medida os registros e as estratégias empregadas pelos alunos se tornam mais ou menos significativos com o uso de figuras ou imagens.

Por fim, destaco a possibilidade de investigar aspectos que podem ter contribuído ou não para os resultados alcançados e as inferências feitas nas pesquisas, como por exemplo, contexto da prática, perfil dos alunos, prática docente do professor regente, tipos de imagens utilizadas, entre outros.

\section{REFERÊNCIAS}

ARRUDA, Joseane Pinto. Histórias e práticas de um ensino na escola primária: marcas e movimentos da matemática moderna. $312 \mathrm{f}$. Tese (Doutorado em Educação Científica e Tecnológica) - Universidade Federal de Santa Catarina, Florianópolis, 2011.

BARRETO, Maria de Fátima Teixeira, BAUMANN, Ana Paula Purcina, TOLEDO, Mônica Albernaz, BICUDO, Maria Aparecida Viggiani. A pesquisa em educação matemática nas séries iniciais no Brasil. In: Seminário Internacional de Estudos e Pesquisas Qualitativas, 4., Rio Claro. Anais... Rio Claro, 1-13, 2010.

BICUDO, Maria Aparecida Viggiani. Pesquisa Qualitativa e Pesquisa Qualitativa segundo a abordagem fenomenológica. In: Borba, Marcelo de Carvalho; Araujo, Jussara de Loiola. (Org.).

Pesquisa qualitativa em educação matemática. Belo Horizonte: Autêntica, 2004, v. 1, p. 99-112.

Pesquisa qualitativa: segundo a visão fenomenológica. São Paulo: Cortez, 2011.

; KLUBER, Tiago Emanuel. A questão da pesquisa sob a perspectiva da atitude fenomenológica de investigação. Conjectura: Filosofia e Educação, Caxias do Sul, v.18, n.3, p.2440, set./dez. 2013.

BRASIL. Ministério da Educação e do Desporto/ Secretaria da Educação Fundamental. Parâmetros Curriculares Nacionais: matemática. 1ำ e 2o ciclos. Brasília: MEC/SEF, 1997.

. Referencial curricular nacional para a educação infantil. Brasília: MEC/SEF, 1998.

. Secretaria de Educação Básica. Pacto nacional pela alfabetização na idade certa: apresentação. Brasília, MEC/SEB, 2014. 72 p.

BRITO, Ângela Xavier, LEONARDOS, Ana Cristina. A identidade das pesquisas qualitativas: construção de um quadro analítico. Cadernos de Pesquisa, n. 113, p.7-38, jul, 2001.

DUVAL, Raymond. Semiósis e pensamento humano: registro semiótico e aprendizagens intelectuais. Trad. Lênio Fernandes Levy e Marisa Rosâni Abreu da Silveira. São Paulo: Editora Livraria da Física, 2009. (Fascículo I)

$\begin{array}{llllll}\text { (C) ETD-Educação Temática Digital } & \text { Campinas, SP } & \text { v.20 } & \text { n.3 } & \text { p. 700-717 } & \text { jul./set. } 2018\end{array}$


FERREIRA, Norma Sandra de Almeida. As pesquisas denominadas "Estado da Arte". Rev. Educação \& Sociedade, ano XXIII, n. 79, p. 257-272, ago, 2002.

GARDNER, Howard. Inteligências múltiplas: a teoria na prática. Porto Alegre: Artes Médicas, 1993.

GIL, Antônio Carlos. Como elaborar projetos de pesquisa. 4. ed. São Paulo: Atlas, 2002.

OLIVEIRA, Priscilla Rohr Garcez. Alfabetização matemática nos anos iniciais do ensino fundamental: uma leitura dos resultados da pesquisa GERES 2005. 2014. 81 f. Dissertação (mestrado em Educação, Cultura e Comunicação) - Faculdade de Educação da Baixada Fluminense, Universidade Estadual do Rio de Janeiro, Duque de Caxias.

PASSOS, Carmen Lucia Brancaglion. 239 f. As representações matemáticas dos alunos do curso de magistério e suas possíveis transformações: uma dimensão axiológica. Dissertação Mestrado (Faculdade de Educação) - Universidade Estadual de Campinas, Campinas, 1995.

SOARES, Magda. Alfabetização no Brasil - O Estado do conhecimento. Brasília: INEP/MEC, 1989.

SEVERINO, Antônio Joaquim. Metodologia do trabalho científico. 21. ed. rev. ampl. São Paulo: Cortez, 2002.

TAMBARUSSI, Carla Melli, KLÜBER, Tiago Emanuel. Modelagem matemática na educação matemática: o que se tem pesquisado? In: Conferência Nacional sobre Modelagem na Educação Matemática, 8., Santa Maria. Anais... Santa Maria, 1-15, 2013.

TAXA, Fernanda de Oliveira Soares. Estudo sobre a resolução de problemas verbais aritméticos nas séries iniciais. 203 f. Dissertação Mestrado (Faculdade de Educação) - Universidade Estadual de Campinas, Campinas, 1996.

VERGNAUD, Gérard. La théorie des champs conceptuels. Recherche en Didactique des Mathématiques. Grenoble: La Pensée Sauvage, v. 10, n. 2/3, p. 133-170, 1990.

VIANA, Odaléa Aparecida. O conhecimento geométrico de alunos do CEFAM sobre figuras espaciais: um estudo das habilidades e dos níveis de conceito. 249 f. Dissertação Mestrado (Faculdade de Educação) - Universidade Estadual de Campinas, Campinas, 2000.

WICHNOSKI, Paulo, KLÜBER, Tiago Emanuel. Uma revisão crítica da tendência Investigação Matemática no Brasil. In: Conferência Interamericana de Educação Matemática, 14., Tuxtla Gutiérrez. Anais... México, 1-9, $2015 a$.

. Uma hermenêutica da produção sobre investigação Matemática no Brasil. Educação Matemática Pesquisa, São Paulo, v.17, n.2, p.173-190, 2015b.

\footnotetext{
${ }^{\mathrm{i}}$ Revisão gramatical sob a responsabilidade de: Solange Aparecida Cecato E-Mail: solangececato@hotmail.com
} 